\title{
Is "Failure to treat" a Treatment failure?
}

SADJ October 2021, Vol. 76 No. 9 p568-p570

LM Sykes, ${ }^{1}$ A Jagathpal ${ }^{2}$, C Bradfield ${ }^{3}$, M Cronje ${ }^{4}$

\begin{abstract}
Over-servicing in dentistry has been widely reported on and censured due to the potential physical, social and financial harms it can cause a patient. In contrast, under-treatment is less often noticed or raised as a concern as it seldom presents with overt signs of carelessness or disregard. In addition, it is usually not accompanied by any time or financial burdens, thus patients rarely complain about it. While some practitioners may argue that failure to treat is a form of negligence, this paper will explore if, and when it could be justified. While practitioners may never reach a consensus agreement, the ultimate message is that all treatment should be patient centred and should only commence following their educated, considered, autonomous, and voluntary consent.
\end{abstract}

\section{INTRODUCTION}

Over servicing in dentistry by means of carrying out unnecessary, inappropriate, excessive or fraudulent treatment has been the focus of many ethical, legal and professional altercations. It occurs when practitioners carry out any form of procedure that is "not medically or clinically indicated, not in accordance with recognised treatment protocols, and without regard for the patient's finances or best interests". ${ }^{1}$ This includes provision of unnecessary treatment that will produce little if any improvement in the patient's health outcomes. ${ }^{2}$ Not providing or delaying treatment falls at the opposite end of the spectrum, and may result in clinicians being accused of "failure to treat" or "supervised neglect". ${ }^{3}$ This paper will use an actual patient case to discuss and debate if no treatment may at times be justified and deemed the most appropriate and best management choice.

\section{Literature review}

Over servicing refers to the provision of unnecessary, excessive or ineffective procedures. Examples include accepting perverse incentives for preferential use of drugs, diagnostic aids, investigations or restorative materials; performing dat-

\footnotetext{
Author affiliations:

1. Leanne M Sykes: BSc, BDS, MDent, IRENSA, Dip Forensic Path, Dip ESMEA, Head of Department of Prosthodontics, University of Pretoria

2. Avish Jagathpal: BDS, MDent (Pros), Private practitioner and consultant Department of Prosthodontics, University of Pretoria

3. Charles Bradfield: $B$ Tech, BChD, Dip Aesthetics; Registrar Department of Prosthodontics, University of Pretoria

4. Michael Cronje: Final year dental student, University of Pretoria

Corresponding author: Leanne Sykes

Head of Department of Prosthodontics, University of Pretoria

Email: Leanne.sykes@up.ac.za.

https://orcid.org/0000-0002-2002-6238

\section{Author contributions:}

Leanne M Sykes: Primary author - 60\%

Avish Jagathpal: $15 \%$

Charles Bradfield: 15\%

Michael Cronje: $10 \%$
}

ed and more aggressive interventions than recommended; treating conditions that were asymptomatic and not likely to cause problems, carrying out purely cosmetic work; concealing all information and depriving patients the opportunity to make autonomous, and informed decisions; or treating conditions where a more preventative approach would have been better. ${ }^{2}$ Given that all of these could result in some form of harm, they may be considered malpractice.

Supervised neglect describes "a situation where a patient's oral health has been allowed to deteriorate over time, despite their regular dental visits". ${ }^{3}$ This is not the same as where the patient's oral health has deteriorated despite the dentist's best efforts and concerns. One way to differentiate between them is to look at the patient's clinical records. If the dentist had correctly identified the patient's problems, carried out appropriate investigations, diagnosed the situation and presented the patient with a comprehensive treatment plan and options, but the patient had "declined the recommendations for treatment", the records would reveal this. In that case, the dentist would have been justified to have only monitored their condition, and not guilty of neglect or malpractice.

A different situation arises with patients who present with many unexpected emergencies, as they often risk not having other necessary procedures dealt with. ${ }^{4}$ Here too, the dentist cannot be accused of supervised neglect if they inform the patient of the need for follow up interventions and the patient does not do so. A clinician may also have observed some "less than optimal restorations over several years and seen little or no deterioration in them". If the patient has remained asymptomatic, they may have felt justified not to replace these. Provided the patient was aware of this "planned inactivity" and agreed with the cautious approach, the dentist cannot be guilty of any wrongdoing.

Determining supervised neglect is never easy, as dentists tend to "look more critically" at work carried out by others, than if they had performed the procedures themselves. ${ }^{3}$ However, there are some clear cut cases where neglect is indisputable, such as when the dentist does not focus on the patient's needs; where they may be physically or mentally unwell, but continue to work in a compromised state; where they are too busy and then neglect treating each patient comprehensively; or where they "assume" a patient will not be interested in certain procedures and do not offer them the options. ${ }^{3,4}$ In all of these cases, there may not be actual malpractice but there is certainly clear negligence. A very different scenario is where the patient presents with a sub-optimal oral condition and has teeth that need treatment, yet is comfortable, pain and infection free, and does not wish to have these teeth worked on. The dentist too may be cognisant that "helping always carried a risk of

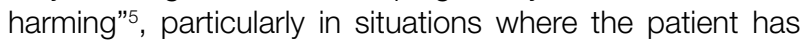
asymptomatic, but severely compromised teeth. They may adopt a philosophy of never causing a patient to leave their 


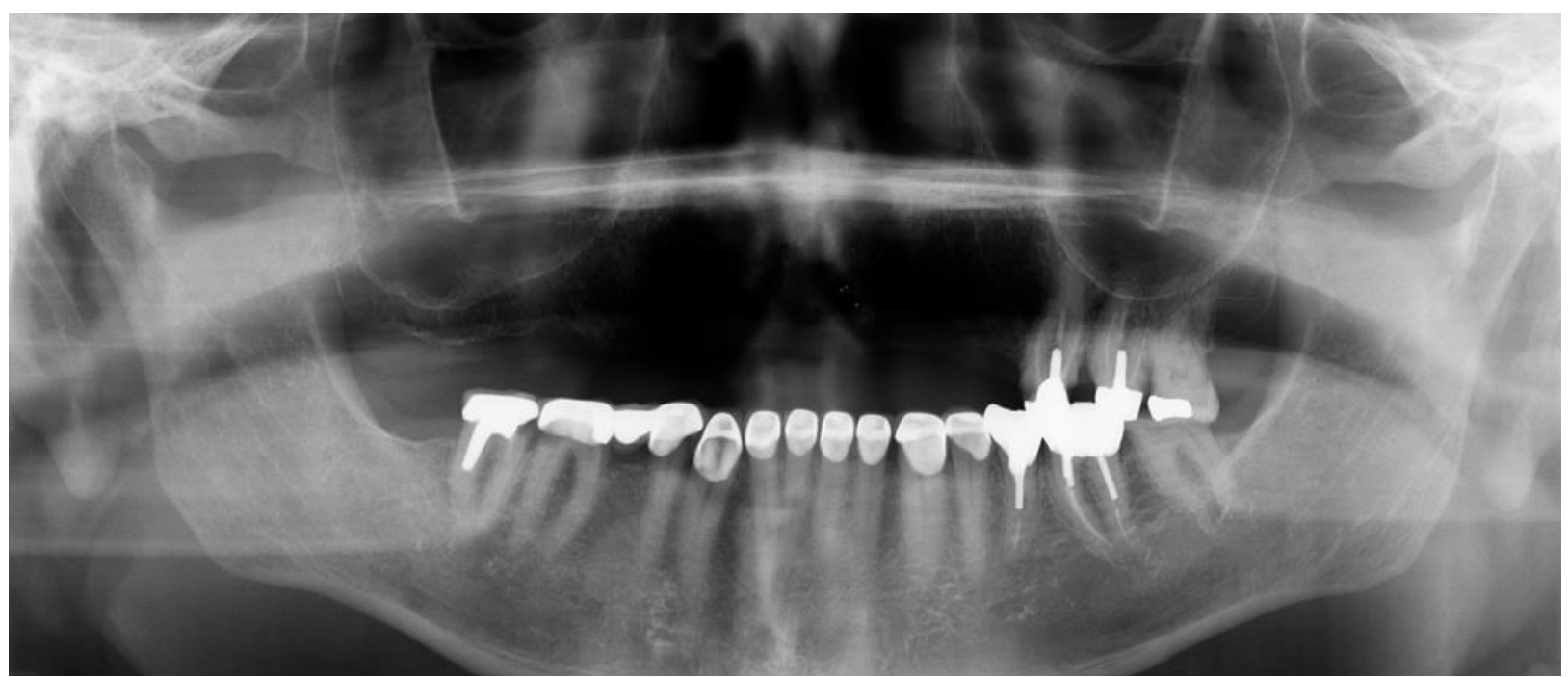

Figure 1. Panoramic radiograph taken on the day of patient presentation
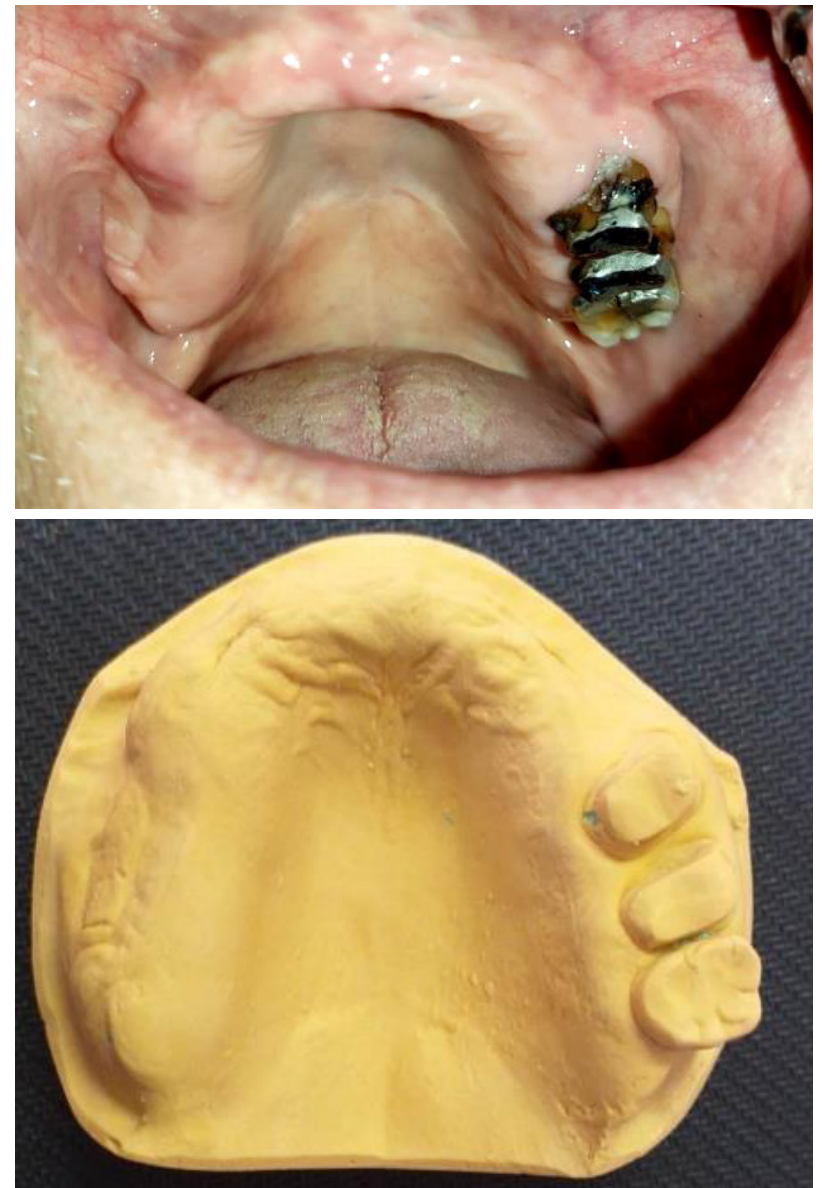

Figure 2. a) Intra oral view of maxilla showing lost crowns on the 25 and $26.2 b$ ) Study cast of the maxilla.

rooms worse off than when they arrived, and consciously chose planned inactivity. It is important to note that this is not the same as a situation where a patient refuses treatment despite recommendations for its need.

\section{Case presentation}

A 76-year-old male patient presented for treatment requesting a maxillary partial denture. Based on his history and clinical examination it was evident that he had received extensive dental treatment in the past, with every tooth in his mouth having some form of restoration. Despite this, he had lost all but three of his maxillary teeth and the mandibular dentition had many failing restorations in need of attention. A detailed intra oral examination and radiographic analysis revealed the following: teeth 25 and 26 had poor endodontics, post and cores and had previously had crowns placed. The patient said these had fallen off years ago and as there was no pain, he had not bothered to get them re-cemented. The mandible had a broken down 37, post core crowns on the 36 and 35 , full coverage crowns on the 34 to the 43 , a failing three-unit bridge from the 44 to the 46 and a failing post core crown on the 47 .

An ideal treatment plan was drawn up and the patient was advised that many teeth needed root canal treatment or retreatment and may even be lost depending on the clinical findings. He responded that he was pain-free, none of his teeth were worrying him, and was said that he did not want to have any further restorative work done. He added that his remaining teeth had served him well for many years and he didn't want to risk losing any more teeth unless they started to give him trouble. He was adamant that he only wanted to have a maxillary partial denture made. After a lengthy discussion, the clinician agreed to this on the understanding that the patient had been fully informed and had actively refused any other treatment.

\section{DISCUSSION}

In this case the dentist agreed to provide the patient with a partial denture, but also explained in deatil about the poor periodontal status of his mandibular teeth, and the need to have this addressed. The patient did concede to consider this suggestion. As such, the treatment provided cannot be considered under-servicing, negelct or malpractice. However it would be prudent if the dentist also monitored the patient, and followed up with reminders if he didn't return for the periodontal therapy.

The principle of beneficence (doing good) ${ }^{5}$ is a reminder that clincians' primary obligation is to their patients. As such when faced with any treatment decision, giving advice or making recommendations, they need to not only ensure it is based on the latest scientific evidence, but must 

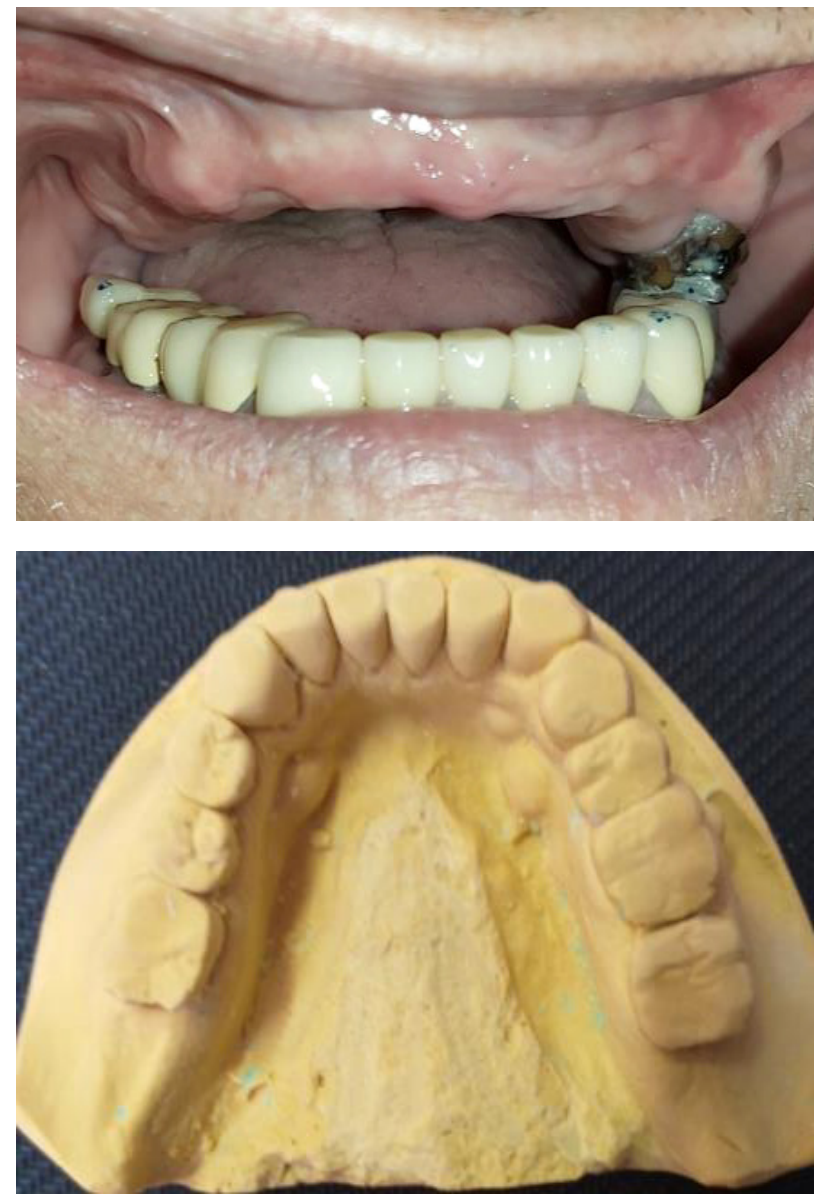

Figure 3. a) Intra oral view of mandible showing heavly restored dentition b) Study cast of the mandible

also consider whether it is in the patient's best interest and approporate for their current situation..$^{3,6}$ Inadequate treatment, failure to diagnose pathology or performing work that does not meet the standard of care is clearly unethical and not in contention. However, undertreating raises many different questions. ${ }^{4}$ The dentist may feel that the situation is relatively stable and could a adopt a "watch and see" approach.

Alternatively they may feel that given the patient's dental history and current situation, the deterioration is likely be progressive and tooth loss is inevitable. In both cases they could justify their inactivity on the grounds that they will be saving the patients time, expense or discomfort by not intervening. They may truly believe their decision is based on the patient's best interests. Their actions could be defensible if they have also fully explained the situation to the patient, provided them with insight into the pros and cons of all treatment options as well as risks associated with no treatment, and allowed them to make an educated, autonomous decision based on their own needs and concerns. ${ }^{4}$ To safeguard themselves, all discussions and decisions must be clearly documented in the patients record files.

A contrary view is that of the clinician who believes that "professionals have a duty to protect patients from harm and promote their welfare". ${ }^{4}$ To this end they feel obliged to "provide competent and timely delivery of dental care within the bounds of clinical circumstances", taking into account the patients needs, desires and values. ${ }^{4}$ If the patient's wish- es and priorities are in contradiction to their expert opinion and ethical duty of care they may resolve to refuse to treat or provide piecemeal services. While this may be seen as a paternalistic approach, it allows them to remian true to their convictions or moral ethos.

While practitioners may differ in their opinions and treatment philosophies, the ultimate question to be answered is whether limited treatment can be justified or has the patient suffered from supervised neglect because of it. In the present case scanario, the dentist had carried out a comprehensive examination and identified all the areas of concern. These had been discussed with the patient including an explanation of the risks and benefits associated with treatment and with no intervention. The patient understood the choices and had consciously chosen minimal intervention. The failure to treat was thus not a falure in performance on the part of the clincian. In supervised neglect the dentist may have either not identified the dental pathology, or not informed the patient of this and as such denied him the opportunitty of having it addressed. Faiulre to treat could then be deemed poor practice or neglect.

In this case scenario, the authors had conflicting opinions. Some agreed to not treat the remianing maxillary teeth and to provide the denture as desired. While another said that "if I cannot do ideal treatment then I will refuse to treat at all". All of them however did agree that the periodontal status should not be ignored. Both approaches can be justified in terms of their individual work ethos, provided the patient was fully informed, and ultimaltey made the final autonomous and educated decision for themselves.

\section{CONCLUSION}

When faced with difficult treatment choices and clinical dilemmas the practitioners should consider all the options bearing in mind the code of ethics set out by The American Dental Association. This states "Professionals have a duty to be honest and trustworthy in their dealings with people. As such, the dentist's primary obligations include respecting the position of trust inherent in the dentist-patient relationship, communicating truthfully and without deception, and maintaining unfaltering integrity at all times". ${ }^{4}$

\section{References}

1. Moodley K, Naidoo S. Ethics and the Dental team. Pretoria, Van Schaik publishers 2010; 38-41

2. Kazemian A, Berg I, Finkel C, et al. How much dentists are ethically concerned about over treatment; a vignette-based survey in Switzerland. BMC Med Ethics; 2015; 16:43. doi: 10.1186/s12910-015-0036-6

3. Dental Protection Organization. Undertreatment and supervised neglect. Accessed at:https://www.dentalprotection.org/uk/articles/undertreatment-and-supervised-neglect. Accessed on: 14-05-2021

4. Howley T. Ethical moment. How to handle a colleague who regularly does not inform his or her patients of all needed treatment? JADA. 2017; 148 (11) 855-857

5. Beauchamp TI, Childress JF. Principles of Biomedical Ethics.5th Ed. New York: Oxford University Press; 2001

6. Palcanis K. Ethical moment. How to I deal with what I perceive to be overtreatment by another dentist? JADA. 2011;142 (4) 447-448 